\title{
A Novel Targeted Screening Tool for Hypogammaglobulinemia: Measurement of Serum Immunoglobulin (IgG, IgM, IgA) Levels from Dried Blood Spots (Ig-DBS Assay)
}

\author{
Leman Yel ${ }^{1,2}$ - Christopher J. Rabbat ${ }^{3}$. Charlotte Cunningham-Rundles ${ }^{4}$. \\ Jordan S. Orange $^{5}$. Troy R. Torgerson ${ }^{6}$. James W. Verbsky ${ }^{7}$. Yeong Wang ${ }^{8}$. \\ Maoyong $\mathrm{Fu}^{9} \cdot$ Terry S. Robins ${ }^{9} \cdot$ Marc S. Edwards ${ }^{9} \cdot$ Jesper Nymann-Andersen ${ }^{9}$
}

Received: 28 April 2015 / Accepted: 27 July 2015 / Published online: 16 August 2015

(C) The Author(s) 2015. This article is published with open access at Springerlink.com

\begin{abstract}
Purpose To develop an assay to quantify serum immunoglobulin ( $\operatorname{IgG}, \operatorname{IgM}, \operatorname{IgA}$ ) levels using dried blood spots (DBS) obtained on collection cards to be used as a tool for targeted screening for hypogammaglobulinemia.

Methods DBS samples, along with simultaneous serum samples, were collected from 107 healthy individuals (11 months to 57 years of age). After eluting proteins from DBS, IgG, IgM, and IgA were quantified by an enzyme-linked immunosorbent assay (ELISA). The Ig-DBS assay was validated through calibration curve performance, intra- and inter-assay precision, accuracy, specificity, selectivity, and linearity. The ELISA measurements were compared with serum Ig levels obtained using a standard nephelometry assay on serum samples collected simultaneously with the DBS samples and the results of the two assays were correlated. The stability of IgG,
\end{abstract}

Leman Yel

leman.yel@baxalta.com

1 Baxalta US, Inc., Global Clinical Research, One Baxter Way, Westlake Village, CA 91362, USA

2 University of California, Irvine, CA, USA

3 Baxalta US, Inc., North American Medical Affairs, Bannockburn, IL, USA

4 Mount Sinai School of Medicine, New York, NY, USA

5 Texas Children's Hospital, Baylor College of Medicine, Houston, TX, USA

6 University of Washington and Seattle Children's Hospital, Seattle Children's Research Institute, Seattle, WA, USA

7 Medical College of Wisconsin, Milwaukee, WI, USA

8 Baxalta US, Inc., Global Quality, Westlake Village, CA, USA

9 Quest Diagnostics, Valencia, CA, USA
$\operatorname{IgM}$, and $\operatorname{IgA}$ in the DBS was tested at room temperature, $36^{\circ}$ to $38^{\circ} \mathrm{C}, 2$ to $8^{\circ} \mathrm{C}$, and -25 to $-40^{\circ} \mathrm{C}$, from 4 to 14 days.

Results The Ig-DBS assay demonstrated precision, accuracy, specificity, selectivity, and linearity. Using the identified correlation coefficients of 0.834 for $\operatorname{IgG}, 0.789$ for $\operatorname{IgM}$, and 0.918 for IgA, the standard nephelometry-based normal reference ranges for all 3 serum Ig isotypes could be used with the Ig-DBS assay in individuals $\geq 16$ years of age. The DBS samples were stable for 14 days at room temperature in a closed polyethylene bag.

Conclusions The Ig-DBS assay is both sensitive and accurate for quantification of serum immunoglobulins. Samples are sufficiently stable at ambient temperature to allow for convenient shipping and analysis at a centralized laboratory. This assay therefore presents a new option for screening patients $\geq 16$ years of age for hypogammaglobulinemia in any setting.

Keywords DBS · dried blood spots · ELISA · Ig-DBS assay · immunoglobulin $\cdot$ nephelometry $\cdot$ primary

immunodeficiency $\cdot$ validation

\section{Introduction}

Primary immunodeficiency diseases (PIDs) are a heterogeneous group of more than 200 disorders that result from a large number of different genetic abnormalities affecting the innate and adaptive immune systems [1]. It has been estimated that there are about 250,000 patients in the United States who have been diagnosed with PID, and many others still to be identified [2]. Worldwide, PIDs are more common than generally thought $[3,4]$. Antibody deficiencies account for more than half (50.9\%) of all immunodeficiency disorders [4]. This heterogeneous group of disorders is characterized by impaired 
antibody production leading to low quantity and/or quality of antibodies [5]. Unfortunately, these disorders are likely to go undiagnosed for years, delaying initiation of appropriate therapy [6].

Many types of PID involving antibody deficiency can be effectively managed by administering immunoglobulin (Ig). In this context, Ig therapy has been shown to significantly decrease the risk of infections and improve quality of life [7-10]. Early diagnosis and treatment lead to better clinical outcomes with decreased risk for morbidity and mortality $[6,11-14]$.

To improve early diagnosis of PID, several initiatives starting with awareness campaigns have been introduced $[15,16]$. Development of newborn screening programs for severe combined immunodeficiency (SCID) changed the paradigm for detecting PID from that of identifying patients after they suffer infectious complications from their disease to that of prospectively screening large populations before the manifestations of their disease become clinically apparent [17-23]. Currently, the US Department of Health and Human Services recommends screening for SCID in all newborns by detecting T cell receptor excision circles (TREC) [24]. The platform for TREC testing employs the dried blood spot obtained from neonates for the purpose of congenital disease testing. This provides the flexibility in obtaining the sample as well as uniform access. The detection of severe B cell disorders, such as X-linked agammaglobulinemia, has also been proposed through this vehicle through detection of the $\mathrm{B}$ cell receptor genetic recombination product $[25,26]$.

While these approaches can and do detect the most severe forms of PID, the vast majority of conditions and patients will not be identified via these modalities.

To raise awareness and increase the index of suspicion for PID in general, various lists of suggestive signs and symptoms have been proposed [2, 27-29]. These include recurrent respiratory tract infections (otitis media, sinusitis, bronchitis, pneumonia), gastrointestinal infections, recurrent/ chronic diarrhea, meningitis and/or sepsis, and autoimmunity [2]. Some patients having these manifestations may have hypogammaglobulinemia. Because immunoglobulin levels are abnormal in many PIDs, it is recommended that the initial evaluation of such patients should start with quantitation of serum $\operatorname{IgG}, \operatorname{IgM}$, and $\operatorname{Ig} \mathrm{A}[2,6,30]$.

Nevertheless, the under-diagnosis and substantial diagnostic delays in identifying antibody deficiencies suggest that there continues to be significant barriers to obtaining this important screening test early in the course of disease. In an attempt to decrease one barrier to screening, we developed a simpler targeted screening tool that can be implemented in primary care or specialty clinics to facilitate the timely diagnosis of hypogammaglobulinemia. To do this, we developed a dried blood spot assay for measurement of serum Ig levels that correlates with results obtained using the standard nephelometry assay, remains stable during transport by regular mail service, and permits the collection of samples in any clinical setting.

\section{Methods}

\section{Samples}

All samples were drawn from 107 healthy individuals (50 males and 57 females) ranging in age from 11 months to 57 years, each of whom or their parents/guardians signed consent forms. Blood samples (both venous blood draws and DBS) were obtained simultaneously at the same visit from healthy individuals. Drops of blood were applied to collection cards (IDBS Spot Saver Card, ID Biological Systems, Greenville, SC, USA) (Fig. 1) after performing finger capillary puncture using a lancet. The circles on the collection card were entirely saturated. The collection cards were allowed to dry on a flat surface for approximately $3 \mathrm{~h}$ at room temperature $\left(18{ }^{\circ} \mathrm{C}\right.$ to $25^{\circ} \mathrm{C}$ ), and then were transported to the laboratory inside a polyethylene bag that was contained in a sealed envelope.

\section{Immunoglobulin Elution from DBS Cards}

The DBS specimen was inspected for proper collection and sample integrity. The sample was punched with a Harris UniCore puncher and placed into a $1.5 \mathrm{~mL}$ low protein binding Eppendorf tube with $200 \mu \mathrm{L}$ of elution buffer (phosphatebuffered saline [PBS], $0.05 \%$ Tween-20), and incubated at room temperature for $2 \mathrm{~h}$ on a shaker at 1000 to $1200 \mathrm{RPM}$. It was then cooled to $2{ }^{\circ} \mathrm{C}$ to $8{ }^{\circ} \mathrm{C}$ and shaken for 16 to $18 \mathrm{~h}$ at 1000 to 1200 RPM. The eluate was allowed to reach room temperature and then was either used within $4 \mathrm{~h}$ or frozen at $-20{ }^{\circ} \mathrm{C}$ to be used later within 1 month.

\section{Quantification of IgG, IgM, and IgA by ELISA}

IgG, IgM, and IgA were quantified from eluted DBS samples by standard sandwich ELISA methodology (Human IgG, IgM, and IgA ELISA Ready-SET-Go! ${ }^{\circledR}$ Kits, eBioscience,

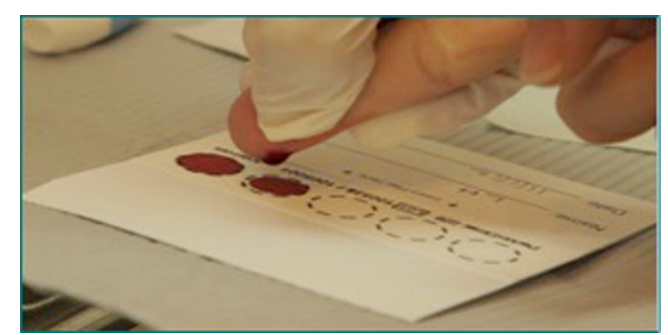

Fig. 1 Blood sample collection using a DBS card. Photo, IDBS spot saver card, ID biological systems, PerkinElmer, Greenville, SC, USA 
San Diego, CA, USA; Tecan GENios Pro Reader platform, Tecan, San Jose, CA, USA). Analyte-specific capture antibody (anti-human IgG, IgM, or IgA) was bound to a 96-well microtiter plate to create the solid phase matrix. Unbound antibody was removed by washing twice with $400 \mu \mathrm{L} /$ well of wash buffer (PBS, $0.05 \%$ Tween-20). Plates were blocked with $250 \mu \mathrm{L}$ of blocking buffer (PBS, $0.10 \%$ Tween-20, $1 \%$ bovine serum albumin) at room temperature for $2 \mathrm{~h}$ and then washed twice with $400 \mu \mathrm{L} /$ well of wash buffer. Following the wash, $100 \mu \mathrm{L}$ of all calibrators/standards and quality control (QC) samples, and patient samples were added to wells in replicates of two. Plates were then sealed and incubated at room temperature for $2 \mathrm{~h}$ with gentle shaking (400 to 450 RPM). Plates were washed 4 times with $400 \mu \mathrm{L} /$ well wash buffer, and $100 \mu \mathrm{L} /$ well of horseradish peroxidase conjugated secondary detection antibody was added. Plates were then sealed and incubated at room temperature for $1 \mathrm{~h}$ with gentle shaking (400 to 450 RPM). Plates were washed 4 times with $400 \mu \mathrm{L} /$ well wash buffer, and $100 \mu \mathrm{L}$ of tetramethylbenzidine substrate solution was added. After the plates were incubated at room temperature for $25 \mathrm{~min}$ and the reaction was stopped with $100 \mu \mathrm{L} 2 \mathrm{~N} \mathrm{H}_{2} \mathrm{SO}_{4}$, the optical density (OD) of each well was read at $450 \mathrm{~nm}$, and adjusted by subtracting the OD of the same well at $550 \mathrm{~nm}$. The immunoglobulin concentrations were quantified using an external standard curve (see below).

\section{Validation for Ig-DBS Assay}

Validation experiments were conducted in accordance with College of American Pathologists (CAP) and Clinical Laboratory Improvement Amendments (CLIA) (1988) standards and regulations as well as good clinical laboratory practices.

\section{Standard Curve Parameters}

An external standard curve for each Ig isotype was constructed using optical densities to quantify the Ig concentration in the DBS eluate in relation to the standard curve. The external standard curves for IgG, IgM, and IgA were developed using 7 standards provided by the manufacturer (eBioscience human IgG, IgM, and IgA ELISA Standards). The standard concentrations specified in the product information ranged from 1.6 to $100 \mathrm{ng} / \mathrm{mL}$ (IgG and $\operatorname{IgA}$ ) and 15.6 to $1000 \mathrm{ng} / \mathrm{mL}(\operatorname{IgM})$.

\section{Quality Control Samples and Limits of Quantitation}

QC samples were prepared by adding IgG, IgM, and IgA (eBioscience human IgG, IgM, and IgA ELISA Standards) to assay diluent at 3 concentrations spanning the range of the standard curve: low-QC, mid-QC, and high-QC (LQC, MQC, and HQC, respectively). Quantitation limits were assessed by analysis of freshly prepared standards in duplicate over 10 independent analytical batches to assess reproducibility and establish limits of quantification. The lower limit of quantitation (LLOQ) and upper limit of quantitation (ULOQ) were defined as the lowest and highest standard concentrations that could be measured within the same limits of precision and accuracy as the standard nephelometry assay $(\leq 25 \%$ coefficient of variation [CV] and $\pm 25 \%$ bias, from the expected value for $\mathrm{IgG}$, and $\leq 15 \% \mathrm{CV}$ and $\pm 15 \%$ bias from the expected value for $\operatorname{IgM}$ and $\operatorname{IgA}$ ). These limits are the Total Allowable Error (TeA) specifications for each of these respective serum analytes on the Siemens Dade Behring BNII instrumentation and nephelometry methodology that was used for correlation during the validation [31-33].

\section{Precision and Accuracy}

Intra-assay precision, the reproducibility of a measurement of an analyte within a single analytical batch, was determined based on the mean of 20 replicates contained in that particular batch. Inter-assay precision, among multiple analytical batches, was calculated at each level based on the mean of 5 replicates of 5 control concentrations of QC generated over 6 batches. Precision limits of $\leq 25 \%$ for IgG and $\leq 15 \%$ for IgM and IgA were used to determine assay acceptability. These limits are the Total Allowable Error (TeA) specifications for each of these respective serum analytes on the Siemens Dade Behring BNII instrumentation and nephelometry methodology that was used for correlation during the validation.

Accuracy, the closeness of a measurement to a known value, was assessed based on comparison of the mean value from the intra-assay batch to the achieved mean of the inter-assay experiment described above for each concentration of QC. Accuracy limits of $\pm 25 \%$ bias for $\operatorname{IgG}$ and $\pm 15 \%$ bias for $\operatorname{IgM}$ and $\operatorname{IgA}$ were used to determine assay acceptability.

\section{Specificity and Selectivity of the Assay}

Specificity is defined as the assay's ability to differentiate and quantify the specific immunoglobulin in the presence of other components of the elution buffer. The effect of elution buffer alone and samples with IgG, IgM, or IgA concentrations below LLOQ on the assay method were evaluated by analyzing 6 different preparations of the elution buffer. Any measurable presence of interfering elution buffer components was acceptable if the measurement was $\leq 20 \%$ of the LLOQ for the analyte and if $80 \%$ of the 6 different preparations met this criterion.

Selectivity of an assay is defined as the ability of the method to differentially measure a particular immunoglobulin isotype in a complex medium without interference by other components of the mixture. To test the selective detection of $\mathrm{IgG}$, IgM, and IgA, the cross-reactivity of the conjugated secondary detection antibody in matrix was analyzed in replicates of 10 for 3 different concentrations of each immunoglobulin 
sample). The cross-reactivity response was measured and calculated using a standard curve. A signal below LLOQ was considered acceptable for selectivity.

\section{Linearity of Dilution}

The analytical measurement range (AMR) for the assay was established by dilutional linearity. Linearity was defined as the ability of the assay, within a specified range, to produce results that are directly proportional to the concentration of immunoglobulin in the elution buffer. Dilutional linearity was expressed in terms of \% bias, a measure of the agreement between the achieved mean and the expected value. Achieved mean values were compared with the expected values by linear regression and considered acceptable if they were within the criteria of \pm 2 times the maximum allowable $\% \mathrm{CV}$ of $25 \%$ for $\mathrm{IgG}$ and $15 \%$ for IgA and IgM, following established CAP/CLIA guidelines for these immunoglobulin isotypes.

Two DBS samples for each immunoglobulin isotype, one representing a high serum Ig level $(1350 \mathrm{mg} / \mathrm{dL}$ for $\mathrm{IgG}$, $275 \mathrm{mg} / \mathrm{dL}$ for IgM, and $272 \mathrm{mg} / \mathrm{dL}$ for IgA) and the other representing a low serum Ig level $(870 \mathrm{mg} / \mathrm{dL}$ for $\mathrm{IgG}$, $80.5 \mathrm{mg} / \mathrm{dL}$ for IgM, and $164.5 \mathrm{mg} / \mathrm{dL}$ for IgA), as determined by the US Food and Drug Administration-approved automated nephelometry assay (Siemens Dade Behring BN II Nephelometer assay), were evaluated for precision and accuracy from 4 replicates of each dilution. The maximum and minimum dilutions for each isotype were established defining the AMR.

\section{Correlational Studies}

The correlational studies compared the immunoglobulin ( $\mathrm{IgG}$, IgM, IgA) concentrations obtained using the Ig-DBS assay on DBS eluates with those obtained using the standard nephelometry assay on serum samples from the same patients. A key objective of these studies was to determine whether or not the reference ranges for IgG, IgM, and IgA established with the standard nephelometry assay could also be employed for the Ig-DBS assay.

\section{Data Analysis}

Results from the two assays were compared and a Pearson correlation equation was developed to convert or normalize the Ig-DBS assay value (which is non-normalized, raw data) to a nephelometry serum-equivalent value. The correlation equation obtained from the measured correlation data for IgG, IgM, and IgA was used to generate the normalized dataset. Results obtained by normalizing the Ig-DBS data were compared with the serum non-normalized data to evaluate for any potential bias $(\%$ bias $=[$ Ig-DBS value minus nephelometry value] divided by nephelometry value] multiplied by 100).
Reference ranges for $\operatorname{IgG}$, IgM, and $\operatorname{IgA}$ were verified using samples from 40 normal adults who had Ig-DBS values and standard nephelometry serum assay values. The Ig-DBS values were normalized using the Pearson correlation equation, and the normalized values were assessed for whether they were within the reference range for adults.

\section{Sample Stability}

The stability of $\operatorname{IgG}, \operatorname{IgM}$, and $\operatorname{IgA}$ in the DBS was tested at room temperature, $36^{\circ}$ to $38^{\circ} \mathrm{C}, 2^{\circ}$ to $8^{\circ} \mathrm{C}$, and $-25^{\circ} \mathrm{C}$ to $-40^{\circ} \mathrm{C}$, from 4 to 14 days. The DBS samples were enclosed in a polyethylene bag placed in a sealed envelope. Stored samples were compared with those assayed without storage and were considered stable if $\%$ bias was $\leq 25 \%$ for $\operatorname{IgG}$ and $\leq 15 \%$ for IgM and IgA, following established CAP/CLIA guidelines for these immunoglobulin isotypes.

\section{Results}

\section{Subjects}

DBS and serum samples were simultaneously obtained from 107 healthy individuals (50 males and 57 females).

\section{Validation for Ig-DBS Assay}

\section{Standard Curve Performance and Limits of Quantitation}

The calibration curve for IgG revealed that precision and accuracy remained within $\pm 24 \%$ for concentrations ranging from 1.6 to $100.0 \mathrm{ng} / \mathrm{mL}$, defining the dynamic range of the assay (i.e., range of antigen concentrations that can be measured accurately), since both concentrations were within the acceptable precision and accuracy parameters $(\leq 25 \% \mathrm{CV}$ and $\pm 25 \%$ bias from the expected value for $\operatorname{IgG}$ ). The IgG LLOQ was set at $3.9 \mathrm{ng} / \mathrm{mL}$. For IgM, the precision and accuracy remained within $\pm 6 \%$ for concentrations ranging from 15.6 to $1000 \mathrm{ng} / \mathrm{mL}$. The IgM LLOQ was set at $49.3 \mathrm{ng} / \mathrm{mL}$. For IgA, the precision and accuracy remained within $\pm 15 \%$ for concentrations ranging from 1.6 to $100.0 \mathrm{ng} / \mathrm{mL}$. This defined the dynamic range of the assay, and the IgA LLOQ was set at $4.5 \mathrm{ng} / \mathrm{mL}$.

\section{Precision and Accuracy}

Five concentrations of QC controls were analyzed 20 times each in one analysis (for each, $n=20$ ) for intra-assay precision. The intra-assay precision for the $\mathrm{IgG} Q \mathrm{QC}$ samples ranged from 6.7 to $17.1 \%$, all values passed the criterion of $\leq 25 \% \mathrm{CV}$. The respective values for IgM and IgA QC samples were 3.6 to $7.1 \%$ and 2.6 to $3.7 \%$, all values for precision passed the criterion of $\leq 15 \% \mathrm{CV}$ (Table 1). 
The intra-assay accuracy for the IgG QC samples ranged from -2.3 to $-17.1 \%$, and all values passed the criterion of $\pm 25 \%$ bias. The respective values for IgM and IgA QC samples were -1.3 to $-11.8 \%$ and -1.5 to $-9.3 \%$, and all values passed the criterion of $\pm 15 \%$ bias (Table 1 ).

Five levels of QC controls were analyzed 6 times (for each, $n=5$ ) for inter-assay precision. The inter-assay precision for the IgG QC samples ranged from 15.2 to $19.1 \%$. All values passed the criterion of $\leq 25 \% \mathrm{CV}$. The respective values for IgM and IgA QC samples were 5.9 to $14.0 \%$ and 4.4 to $11.1 \%$, and all values passed the criterion of $\leq 15 \% \mathrm{CV}$ (Table 1).

The inter-assay accuracy for the IgG QC samples ranged from -7.7 to $-16.9 \%$, and all values passed the criterion of $\pm 25 \%$ bias. The respective values for IgM and IgA QC samples were 4.6 to $7.5 \%$ and -2.6 to $-5.5 \%$, and all values passed the criterion of $\pm 15 \%$ bias (Table 1 ).

\section{Analytical Specificity and Selectivity}

The specificity and selectivity for IgG, IgM, and IgA are shown in Table 2. IgG, IgM, and IgA levels were all below the LLOQ in empty microtiter plates. Capture of IgG by the anti-IgA and anti-IgM antibodies was below the LLOQ. This was also the case for capture of IgM by anti-IgG and anti-IgA antibodies and capture of IgA by anti-IgG and anti-IgM antibodies.

\section{Linearity of Dilution}

A Pearson coefficient of determination $\left(\mathrm{R}^{2}\right)$ of 1.00 between the target dilution concentration and the achieved value was demonstrated over the range evaluated for IgG. Similar results were obtained for IgM and IgA. Percent bias values for IgG ranged from -22 to $12.1 \%$; those for IgM ranged from -1.7 to $10.2 \%$; and those for IgA ranged from -23.5 to $22.1 \%$. All were within the acceptable range of \pm 2 times the $\% \mathrm{CV}$ established for each isotype.

\section{Correlational Studies}

\section{Correlations with Non-normalized Data}

In this analysis, where $x$ is DBS value in $\mathrm{ng} / \mathrm{mL}$ and $y$ is a normalized value in $\mathrm{mg} / \mathrm{dL}$, the regression analysis formula for IgG was $y=48.962 x-17358(n=101)$ and $r=0.834$. For $\mathrm{IgM}$, the regression analysis formula was $\mathrm{y}=121.6 \mathrm{x}+115.13$ $(n=107)$ and $r=0.789$. The regression analysis formula for IgA was $y=38.942 \mathrm{x}-2000.8(n=107)$ and $r=0.918$.

\section{Correlations with Normalized Data}

The normalized values for $\operatorname{IgG}, \operatorname{IgM}$, and $\operatorname{IgA}$ in $\mathrm{mg} / \mathrm{dL}$ were calculated using the above regression analysis formulas. Then, regression formulas using the normalized

Table 1 Intra- and inter-assay precision and accuracy for IgG, IgM, and IgA

\begin{tabular}{|c|c|c|c|c|c|}
\hline QC samples & $\begin{array}{l}\text { Intra-assay } \\
\text { precision (CV\%) }\end{array}$ & $\begin{array}{l}\text { Intra-assay } \\
\text { accuracy (\% bias) }\end{array}$ & QC samples & $\begin{array}{l}\text { Inter-assay } \\
\text { precision (CV\%) }\end{array}$ & $\begin{array}{l}\text { Inter-assay } \\
\text { accuracy (\% bias) }\end{array}$ \\
\hline IgG & & & IgG & & \\
\hline LLOQ (3.2 ng/mL) & 12.3 & -17.1 & LLOQ (3.9 ng/mL) & 19.1 & -16.5 \\
\hline Low QC (7.2 ng/mL) & 10.7 & -16.7 & LQC (8.6 ng/mL) & 18.6 & -7.7 \\
\hline Middle QC (14.2 ng/mL) & 9.5 & -8.6 & MQC (15.6 ng/mL) & 19.9 & -16.9 \\
\hline High QC (33.5 ng/mL) & 6.7 & -2.3 & HQC (34.3 ng/mL) & 15.2 & -8.7 \\
\hline ULOQ (57.7 ng/mL) & 17.1 & -9.2 & ULOQ (63.5 ng/mL) & 16.5 & -15.3 \\
\hline $\operatorname{IgM}$ & & & $\operatorname{IgM}$ & & \\
\hline LLOQ (43.4 ng/mL) & 7.1 & 11.8 & LLOQ (49.3 ng/mL) & 14.0 & 5.1 \\
\hline Low QC (91.8 ng/mL) & 4.4 & -8.7 & LQC (100.5 ng/mL) & 7.5 & 7.2 \\
\hline Middle QC (190.8 ng/mL) & 4.2 & -5.3 & MQC (201.6 ng/mL) & 5.9 & 7.5 \\
\hline High QC (371.2 ng/mL) & 3.6 & -5.4 & HQC (392.3 ng/mL) & 6.6 & 4.6 \\
\hline ULOQ (791.8 ng/mL) & 4.3 & -1.3 & ULOQ (802.5 ng/mL) & 5.9 & 7.0 \\
\hline $\operatorname{Ig} \mathrm{A}$ & & & $\operatorname{Ig} \mathrm{A}$ & & \\
\hline LLOQ (4.0 ng/mL) & 3.7 & -9.3 & LLOQ (4.5 ng/mL) & 11.1 & -4.9 \\
\hline Low QC $(8.5 \mathrm{ng} / \mathrm{mL})$ & 2.7 & -5.9 & Low QC $(9.0 \mathrm{ng} / \mathrm{mL})$ & 7.0 & -3.8 \\
\hline Middle QC (17.0 ng/mL) & 2.6 & -3.9 & Middle QC (17.7 ng/mL) & 5.8 & -5.5 \\
\hline High QC (35.3 ng/mL) & 2.8 & -2.7 & High QC (36.3 ng/mL) & 4.9 & -3.3 \\
\hline ULOQ (71.9ng/mL) & 3.5 & -1.5 & ULOQ (73.0 ng/mL) & 4.4 & -2.6 \\
\hline
\end{tabular}

$C V$ coefficient of variation, $L L O Q$ lower limit of quantitation, $Q C$ quality control, $L Q C$ low range of the dynamic range $\mathrm{QC}, M Q C$ middle of the dynamic range $\mathrm{QC}, H Q C$ high range of the dynamic range $\mathrm{QC}, Q C$ quality control, $U L O Q$ upper limit of quantitation 
Table 2 Specificity and selectivity of the Ig-DBS assay

\begin{tabular}{|c|c|c|c|c|c|c|c|c|}
\hline & \multirow{2}{*}{\multicolumn{2}{|c|}{ Specificity }} & Selectivity & & & & & \\
\hline & & & \multicolumn{3}{|c|}{$\begin{array}{l}\text { Selectivity } \\
\text { IgG calibrator captured by anti-IgA }\end{array}$} & \multicolumn{3}{|c|}{ IgG calibrator captured by anti-IgM } \\
\hline & Matrix & IgG added at $3.1 \mathrm{ng} / \mathrm{mL}$ & $37.5 \mathrm{ng} / \mathrm{mL}$ & $18.75 \mathrm{ng} / \mathrm{mL}$ & $9.38 \mathrm{ng} / \mathrm{mL}$ & $37.5 \mathrm{ng} / \mathrm{mL}$ & $18.75 \mathrm{ng} / \mathrm{mL}$ & $9.38 \mathrm{ng} / \mathrm{mL}$ \\
\hline Mean & $<$ LLOQ & 1.9 & $2.6^{\mathrm{a}}$ & $2.8^{\mathrm{a}}$ & $2.4^{\mathrm{a}}$ & $3.2^{\mathrm{a}}$ & $2.5^{\mathrm{a}}$ & $2.2^{\mathrm{a}}$ \\
\hline SD & - & 0.2 & - & - & - & - & - & - \\
\hline$\% \mathrm{CV}$ & - & 8.9 & - & - & - & - & - & - \\
\hline$\%$ accuracy & - & 62.3 & - & - & - & - & - & - \\
\hline \multicolumn{9}{|c|}{${ }^{\mathrm{a}}<$ LLOQ of $4.7 \mathrm{ng} / \mathrm{mL}$} \\
\hline \multicolumn{9}{|l|}{$\operatorname{IgM}$} \\
\hline & \multirow{2}{*}{\multicolumn{2}{|c|}{ Specificity $^{\mathrm{a}}$}} & \multicolumn{6}{|l|}{ Selectivity } \\
\hline & & & \multicolumn{3}{|c|}{ IgM calibrator captured by anti-IgA } & \multicolumn{3}{|c|}{ IgM calibrator captured by anti-IgG } \\
\hline & Matrix & IgM added at $15.6 \mathrm{ng} / \mathrm{mL}$ & $375.0 \mathrm{ng} / \mathrm{mL}$ & $187.5 \mathrm{ng} / \mathrm{mL}$ & $93.8 \mathrm{ng} / \mathrm{mL}$ & $375.0 \mathrm{ng} / \mathrm{mL}$ & $187.5 \mathrm{ng} / \mathrm{mL}$ & $93.8 \mathrm{ng} / \mathrm{mL}$ \\
\hline Mean & $<$ LLOQ & $<$ LLOQ & $<$ LLOQ & $<$ LLOQ & $<$ LLOQ & $<$ LLOQ & $<$ LLOQ & $<$ LLOQ \\
\hline \multicolumn{9}{|c|}{${ }^{\mathrm{b}} \mathrm{LLOQ}=46.9 \mathrm{ng} / \mathrm{mL}$} \\
\hline \multicolumn{9}{|c|}{$\operatorname{IgA}$} \\
\hline & \multicolumn{2}{|c|}{ Specificity } & \multicolumn{6}{|l|}{ Selectivity } \\
\hline & & & \multicolumn{3}{|c|}{ IgA calibrator captured by anti-IgG } & \multicolumn{3}{|c|}{ IgA calibrator captured by anti-IgM } \\
\hline & Matrix & IgA added at $3.1 \mathrm{ng} / \mathrm{mL}$ & $37.5 \mathrm{ng} / \mathrm{mL}$ & $18.75 \mathrm{ng} / \mathrm{mL}$ & $9.38 \mathrm{ng} / \mathrm{mL}$ & $37.5 \mathrm{ng} / \mathrm{mL}$ & $18.75 \mathrm{ng} / \mathrm{mL}$ & $9.38 \mathrm{ng} / \mathrm{mL}$ \\
\hline Mean & $<$ LLOQ & 2.8 & $1.1^{\mathrm{a}}$ & $1.1^{\mathrm{a}}$ & $1.1^{\mathrm{a}}$ & $4.2^{\mathrm{a}}$ & $2.5^{\mathrm{a}}$ & $1.8^{\mathrm{a}}$ \\
\hline SD & - & 0.1 & - & - & - & - & - & - \\
\hline$\% \mathrm{CV}$ & - & 3.7 & - & - & - & - & - & - \\
\hline$\%$ accuracy & - & 88.6 & - & - & - & - & - & - \\
\hline
\end{tabular}

$C V$ coefficient of variation, $L L O Q$ lower limit of quantitation, $S D$ standard deviation

${ }^{a}$ The assay was unable to quantify analyte added to matrix at $15.6 \mathrm{ng} / \mathrm{mL}$ as well as in matrix without added analyte, thereby demonstrating specificity

${ }^{\mathrm{b}}$ Results in the assay for all concentrations that are below the LLOQ of $46.9 \mathrm{ng} / \mathrm{mL}$ for the assay indicate no selectivity issue

values were established. The regression analysis formula for IgG was $y=1.000 x+0.0068(n=101)$ and $r=0.834$ (Fig. 2a). The average bias and those at the low and high medical decision level ranges (694 and $1618 \mathrm{mg} /$ $\mathrm{dL}$, respectively) were all $0.0 \%$. The maximum allowable bias was $\pm 25 \%$. For IgM, the regression analysis formula was $y=1.000 x-0.00005(n=107)$ and $r=0.789$ (Fig. 2b). The average bias and those at the low and high medical decision level ranges (48 and $271 \mathrm{mg} / \mathrm{dL}$, respectively) were all $0.0 \%$. The maximum allowable bias was $\pm 15 \%$. For IgA, the regression analysis formula was $y=1.0001 x-0.001 \quad(n=107)$, and $r=0.918$ (Fig. 2c). The average bias and those at the low and high medical decision level ranges ( 81 and $463 \mathrm{mg} / \mathrm{dL}$, respectively) were all $0.0 \%$. The maximum allowable bias was $\pm 15 \%$.

\section{Reference Ranges}

Forty subjects had simultaneous blood draws for serum samples and also provided samples for DBS. The IgG, IgM, IgA tests were run on all 40 samples in order to verify that the reference ranges used by Quest Diagnostics and other laboratories for the nephelometry assay are applicable to this normal population. Determination of whether the reference ranges for the standard nephelometry serum assay could also be applied to the Ig-DBS was accomplished by comparing numbers of results outside the reference ranges for $\operatorname{IgG}, \operatorname{IgM}$, and $\operatorname{IgA}$ for each of the assays. The reference range for IgG in male and female individuals $\geq 16$ years of age was 694 to $1618 \mathrm{mg} / \mathrm{dL}$. Results for 39 of the 40 subjects were within this range for both the standard nephelometry and Ig-DBS assays. The reference range for IgM in male and female individuals $\geq 16$ years of age was $48-271 \mathrm{mg} / \mathrm{dL}$. Results for 35 of 40 subjects were within this range for both the standard nephelometry and IgDBS assays. When the DBS values were converted or normalized to serum $\mathrm{mg} / \mathrm{dL}$ values, 4 serum and 4 DBS normalized results independent of the source individual were outside the reference range ( 1 above and 3 below). The reference range for IgA in male and female individuals $\geq 16$ years of age is 81 to $463 \mathrm{mg} / \mathrm{dL}$.

For IgG, the LLOQ and ULOQ of the Ig-DBS assay were established at $3.9 \mathrm{ng} / \mathrm{mL}$ and $63.5 \mathrm{ng} / \mathrm{mL}$, respectively. This result, combined with the established linearity of dilution of 

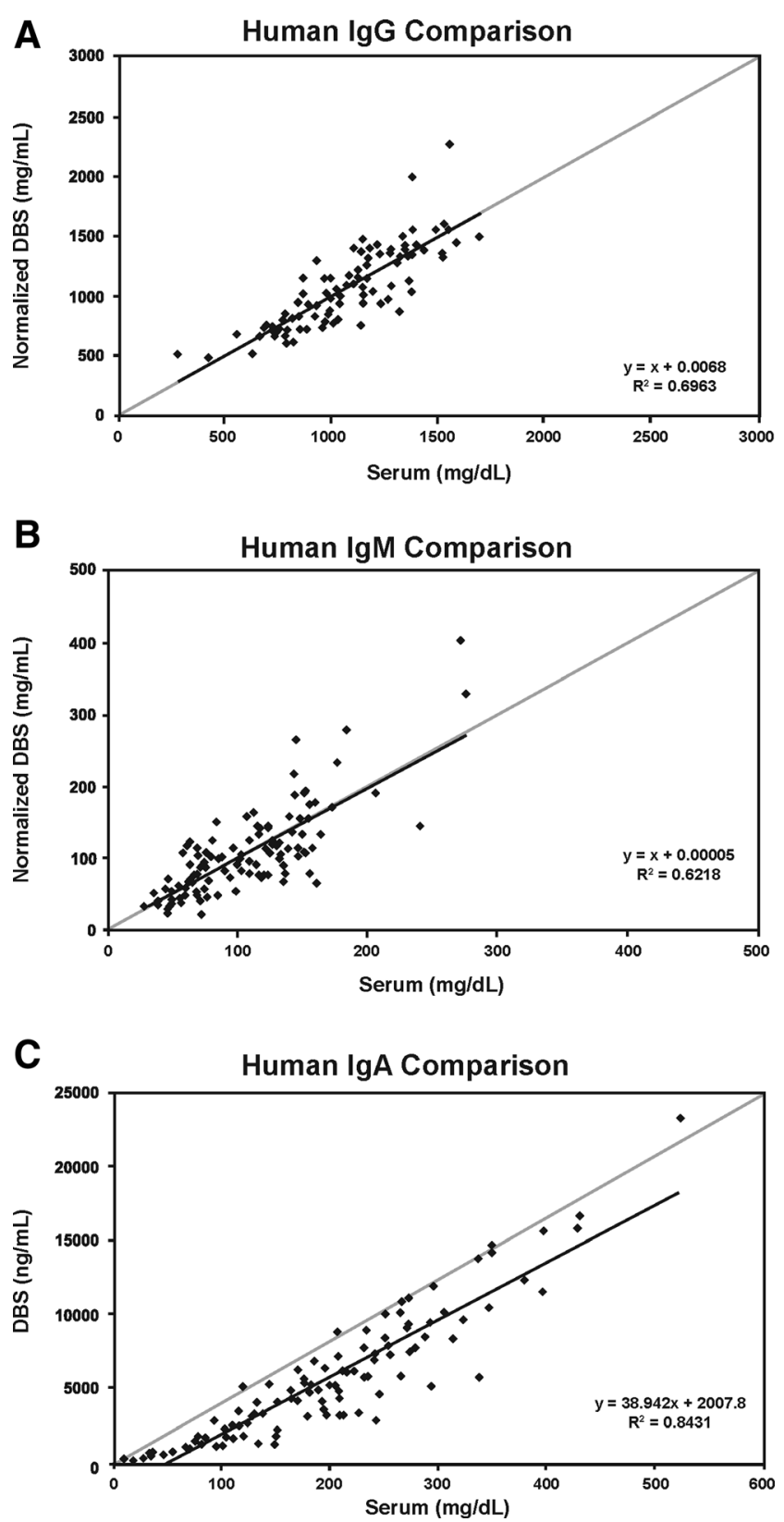

Fig. 2 Correlations between standard nephelometry assay and Ig-DBS for $\operatorname{IgG}(\mathbf{a}), \operatorname{IgM}(\mathbf{b})$, and $\operatorname{IgA}$ (c) (scatterplot and regression line)

DBS samples and the correlation equations derived from the DBS and serum assays, generated a normalized low of $370 \mathrm{mg} / \mathrm{dL}$ and a high of $6832 \mathrm{mg} / \mathrm{dL}$ for the reportable values range, respectively. The reference range for $\operatorname{IgG}$ in the standard nephelometry assay for males and females in the age range $\geq 16$ years was 694 to $1618 \mathrm{mg} / \mathrm{dL}$ and fell within these limits. For IgM, the LLOQ and ULOQ of the Ig-DBS assay were established at $49.3 \mathrm{ng} / \mathrm{mL}$ and $802.5 \mathrm{ng} / \mathrm{mL}$, respectively. Combined with the established linearity of dilution for DBS samples, this generated a normalized low and high of 9 and $6581 \mathrm{mg} / \mathrm{dL}$ for the reportable values range, respectively. The reference range for IgM in the standard nephelometry assay for males and females in the age range $\geq 16$ years was 48 to $271 \mathrm{mg} / \mathrm{dL}$ and was within these limits. For IgA, the LLOQ and ULOQ of the Ig-DBS assay were established at $4.5 \mathrm{ng} / \mathrm{mL}$ and $73.0 \mathrm{ng} / \mathrm{mL}$, respectively. Combined with the established linearity of dilution of DBS samples, this resulted in a normalized low of $63 \mathrm{mg} / \mathrm{dL}$ and a high of $3804 \mathrm{mg} / \mathrm{dL}$ for the reportable values range, respectively. The reference range for IgA in the standard nephelometry assay for males and females $\geq 16$ years of age was 81 to $463 \mathrm{mg} /$ $\mathrm{dL}$, and it also fell within the limits for the Ig-DBS assay.

All these results indicate that the reference ranges for $\mathrm{IgG}$, IgM, and IgA established for individuals $\geq 16$ years of age with the standard nephelometry assay can also be used for the normalized values derived from the Ig-DBS assay. The current study focused on establishing the IgDBS assay for individuals $\geq 16$ years of age since the normal adult reference ranges apply to this group; which made it possible to evaluate the assay without the added complexity of age-adjusted normal values that are typically lower in younger children. Sample results from younger children were used only as anchor points for establishment of the regression equations at the lower end of the range.

\section{Stability of DBS}

When stored in a polyethylene bag, $\operatorname{IgG}, \operatorname{IgM}$, and $\operatorname{IgA}$ were stable ( $\leq 25 \%$ bias for $\operatorname{IgG}$ and $\leq 15 \%$ bias for IgM and IgG) at room temperature and at $2^{\circ}$ to $8{ }^{\circ} \mathrm{C}$ for 14 days. At $36^{\circ}$ to $38^{\circ} \mathrm{C}$, IgG and IgM were stable for 4 days and IgA was stable for 3 days. At $-25^{\circ} \mathrm{C}$ to $-40{ }^{\circ} \mathrm{C}, \operatorname{IgG}$ and $\operatorname{IgM}$ were stable for 14 days and IgA was stable for 10 days (Table 3 ).

\section{Discussion}

Based on the fact that there remains significant diagnostic delay in identifying patients with hypogammaglobulinemia $[6,11]$ there is a need for a convenient, reliable and targeted method to evaluate circulating immunoglobulin levels in order to decrease the threshold to screen for antibody deficiency. Ideally, the screening tool needs to be convenient, simple to use, and able to capture the patient immediately at the site of

Table 3 Days of stability of $\operatorname{IgG}$, IgM, and $\operatorname{IgA}$ in DBS ${ }^{\mathrm{a}}$

\begin{tabular}{lllll}
\hline Analyte & Room temperature & 2 to $8{ }^{\circ} \mathrm{C}$ & 36 to $38{ }^{\circ} \mathrm{C}$ & -20 to $-40{ }^{\circ} \mathrm{C}$ \\
\hline IgG & 14 & 14 & 4 & 14 \\
IgM & 14 & 14 & 4 & 14 \\
IgA & 14 & 14 & 3 & 10
\end{tabular}

${ }^{\text {a }}$ Storage in polyethylene bag

Maximum number of days evaluated at room temperature $=14$; at $2^{\circ}$ $8{ }^{\circ} \mathrm{C}=14$; at $36^{\circ}-38^{\circ} \mathrm{C}=4$; at $-20^{\circ}$ to $-40{ }^{\circ} \mathrm{C}=14$ 
care. It should also be usable in a variety of clinical settings to maximize utility as a potential screening tool for hypogammaglobulinemia. We believe that a simple method that allows sample collection when patients are physically in the clinic will decrease the threshold to screen patients for antibody deficiencies, thereby potentially shortening the delay to diagnosis that is common for these disorders.

Patients with PID sometimes are not diagnosed until they are hospitalized for a life-threatening infection [34]. This was highlighted in a survey of nearly 1300 patients with PID carried out by the Immune Deficiency Foundation. The survey showed that the average duration from symptom onset to diagnosis was 12.4 years for all types of PID, 4.4 years for agammaglobulinemia, and 14 years for common variable immunodeficiency (CVID) [35]. A survey by the Primary Immunodeficiency Association indicated that $57 \%$ of patients in the United Kingdom had to see their primary care physician more than 10 times before being referred to a specialist; for $25 \%$ of adult patients, the time from initial presentation to diagnosis of PID was greater than 7 years [36]. A study of patients with CVID also indicated a mean diagnostic delay of 7 years [37].

DBS samples have been successfully used in various newborn screening tests of genetic diseases for many years. More recently, DBS have been demonstrated to be a convenient blood sample collection device for $\mathrm{T}$ cell receptor excision circle (TREC) analysis in SCID screening [20, 38, 39] and for determination of C3 deficiency [40]. Analysis of kappadeleting recombination excision circles (KREC) using DBS samples has also been developed [25]. The applicability of these assays is however limited to patients with severe $\mathrm{T}$ or $\mathrm{B}$ cell lymphopenia due to defective recombination of the T or $\mathrm{B}$ cell receptor gene locus.

This approach is designed to detect severe immunodeficiencies, many of which are attributable to distinct immunologic and/or genetic mechanisms but it fails to detect the majority of patients who ultimately develop antibody deficiency. The testing platform presented here extends the utility of DBS to quantification of $\operatorname{IgG}, \operatorname{IgM}$, and $\operatorname{IgA}$ as a screening tool for hypogammaglobulinemia in patients 16 years of age and older. We predict that this method will also serve as a screening tool for younger children as well but we have not yet evaluated enough samples from pediatric patients of various age groups to perform adequate validation testing.

There are several advantages of DBS that make this a valuable testing platform for hypogammaglobulinemia screening. First, it allows collection at the point of care or even in a patient's home, which should decrease barriers to having testing performed. Second, it could facilitate rapid, efficient screening of large groups of high-risk individuals at patient or family gatherings. Third, shipping of the card via standard mail, which is much cheaper than sending a liquid blood sample, would facilitate use of this screening test in rural areas or in developing countries where timely shipment of liquid blood samples can be a logistical challenge. Although the DBS described has substantial utility, it should be kept in mind that it is not designed to detect forms of PID that are not associated with decreased Ig levels (e.g., complement deficiency and phagocyte defects) [30]. Thus, normal DBS results should not eliminate the possibility of a PID in a patient with clinical symptoms that would prompt suspicion of this diagnosis.

The present study was carried out to validate the collection of DBS with analysis by ELISA for quantification of serum IgG, IgM, and IgA using standardized experimental samples and serum from individuals expected to have normal immunoglobulin levels. ELISA for measurement of immunoglobulins is much more sensitive than the conventional nephelometry assay, thereby allowing the use of very small quantities of specimen [41-43]. In addition, good correlations between protein concentrations measured with ELISA and nephelometry have been shown in previous studies comparing the two methods $[44,45]$. The Ig-DBS assay we developed demonstrated precision, accuracy, specificity, selectivity, and linearity. The correlation between the Ig-DBS assay and standard nephelometry assay was verified with high correlation coefficients of 0.834 for $\operatorname{IgG}, 0.789$ for IgM, and 0.918 for IgA. It was also determined that normal reference ranges for all 3 serum Ig isotypes from the standard nephelometry assay could be used with the Ig-DBS assay normalized values in individuals $\geq 16$ years of age. Accordingly, the Ig-DBS assay had sufficient clinically reportable ranges (CRR), particularly at the low end, i.e. $370 \mathrm{mg} / \mathrm{dL}$ for $\mathrm{IgG} ; 9 \mathrm{mg} / \mathrm{dL}$ for $\mathrm{IgM}$; and $63 \mathrm{mg} / \mathrm{dL}$ for IgA, to provide a suggestion for comprehensive immunological evaluation. The Ig-DBS results for all 3 serum Ig isotypes are reported as concentrations in $\mathrm{mg} / \mathrm{dL}$ with normal reference ranges. Further costs associated with phlebotomy and shipping of blood tubes are not required for blood sampling by DBS and thus should be considered as reducing the overall cost of a DBS-based approach.

Lastly, we assessed the stability of $\operatorname{IgG}, \operatorname{IgM}$, and $\operatorname{IgA}$ in DBS samples stored in various conditions, information critical to understanding whether this approach would be stable enough to allow for shipping of samples at ambient temperature to a centralized laboratory for processing and measurement. Previous studies of the stability of large biologic molecules in DBS have demonstrated stability for more than 1 week across a wide range of temperatures [46-48]. However, it has also been shown that extreme storage conditions, including high humidity, very high temperature $\left(55^{\circ} \mathrm{C}\right)$, and exposure to daylight for long periods can decrease recovery of large molecules from DBS [49]. Results of this study showed that DBS samples were stable over 14 days at room temperature, 3 days at $36^{\circ}-38^{\circ} \mathrm{C}, 14$ days at $2^{\circ}-8^{\circ} \mathrm{C}$, and $\geq 10$ days at $-25^{\circ}$ to $-40^{\circ} \mathrm{C}$ in a sealed polyethylene bag. Therefore, the Ig-DBS assay should enable transportation of the samples at room temperature via regular mail. 
In conclusion, the Ig-DBS assay is both sensitive and accurate for quantification of serum immunoglobulins with convenient sample collection and shipment. This assay thus presents a potential new alternative for screening patients with suspected hypogammaglobulinemia. As with any screening test, further laboratory evaluation, including repeated measurement of serum Ig levels using standard nephelometry assay in patients with Ig levels at the lower end of the normal range, and referral to a specialist would be recommended for definitive diagnosis.

Acknowledgments We wish to thank Bob Rhoades, PhD, of BSG Communications, for writing assistance. Editorial assistance of BSG Communications, supported by Baxalta US, Inc., is also acknowledged.

Conflicts of Interest and Funding Sources Leman Yel, MD, is an employee of Baxalta US, Inc., Christopher J. Rabbat, PhD, is an employee of Baxalta US, Inc., Charlotte Cunningham-Rundles, $\mathrm{MD}, \mathrm{PhD}$, reports no conflict of interest. Jordan Orange, $\mathrm{MD}, \mathrm{PhD}$, is a consultant for Baxter, CSL-Behring, Atlantic Research Group, and ASD Healthcare, and has received grants from CSL-Behring. Troy R. Torgerson, MD, $\mathrm{PhD}$, is a consultant for Baxter BioSciences and CSL Behring and has also received grants from both companies; he also is a consultant for Questcor Pharmaceuticals. James Verbsky, MD, PhD, has received an overseas research grant from Baxter. Yeong Wang, $\mathrm{PhD}$, is a former employee of Baxalta US, Inc., Mao Yong $\mathrm{Fu}, \mathrm{PhD}$, is a former employee of Quest Diagnostics, Inc. Terry Robins, $\mathrm{PhD}$, is a former employee of Quest Diagnostics, Inc. Marc Edwards, MD, MBA, is an employee of Quest Diagnostics, Inc., and also owns shares of Quest Diagnostics stock. $\mathrm{He}$ is the medical director of the Quest Laboratory where the DBS samples are tested and reported under contract to Baxter Healthcare Corporation. Jesper Nymann-Andersen, PhD, MBA, is a former employee of Quest Diagnostics, Inc.

Open Access This article is distributed under the terms of the Creative Commons Attribution 4.0 International License (http:// creativecommons.org/licenses/by/4.0/), which permits unrestricted use, distribution, and reproduction in any medium, provided you give appropriate credit to the original author(s) and the source, provide a link to the Creative Commons license, and indicate if changes were made.

\section{References}

1. Al-Herz W, Bousfiha A, Casanova JL, Chatila T, Conley ME, Cunningham-Rundles $\mathrm{C}$, et al. Primary immunodeficiency diseases: an update on the classification from the International Union of Immunological Societies Expert Committee for Primary Immunodeficiency. Front Immunol. 2014;5:162.

2. Immune Deficiency Foundation. Diagnostic and clinical care guidelines for primary immunodeficiency disease; 2nd Edition. 2009. http://primaryimmune.org/about-primaryimmunodeficiency-diseases/idf-publications?aid=379\&pid= 275\&sa=1. Accessed 31 March 2015.

3. Bousfiha AA, Jeddane L, Ailal F, Benhsaien I, Mahlaoui N, Casanova JL, et al. Primary immunodeficiency diseases worldwide: more common than generally thought. J Clin Immunol. 2013;33:1-7.

4. Modell V, Gee B, Lewis DB, Orange JS, Roifman CM, Routes JM, et al. Global study of primary immunodeficiency diseases (PI)diagnosis, treatment, and economic impact: an updated report from the Jeffrey Modell Foundation. Immunol Res. 2011;51:61-70.
5. American Academy of Allergy Asthma \& Immunology. Eight guiding principles for effective use of IVIG for patients with primary immunodeficiency. 2011. http://primaryimmune.org/wpcontent/uploads/2011/11/Guiding-Principles-I.pdf. Accessed 31 March 2015.

6. Ballow M, Notarangelo L, Grimbacher B, Cunningham-Rundles C, Stein M, Helbert M, et al. Immunodeficiencies. Clin Exp Immunol. 2009;158 Suppl 1:14-22.

7. Quartier P, Debré M, De Blic J, de Sauverzac R, Sayegh N, Jabado $\mathrm{N}$, et al. Early and prolonged intravenous immunoglobulin replacement therapy in childhood agammaglobulinemia: a retrospective survey of 31 patients. J Pediatr. 1999;134:589-96.

8. Busse PJ, Razvi S, Cunningham-Rundles C. Efficacy of intravenous immunoglobulin in the prevention of pneumonia in patients with common variable immunodeficiency. J Allergy Clin Immunol. 2002;109:1001-4.

9. Skull S, Kemp A. Treatment of hypogammaglobulinaemia with intravenous immunoglobulin, 1973-93. Arch Dis Child. 1996;74: 527-30.

10. Berger M, Murphy E, Riley P, Bergman GE, VIRTUE Trial Investigators. Improved quality of life, immunoglobulin G levels, and infection rates in patients with primary immunodeficiency diseases during self-treatment with subcutaneous immunoglobulin G. South Med J. 2010;103:856-63.

11. Plebani A, Soresina A, Rondelli R, Amato GM, Azzari C, Cardinale $\mathrm{F}$, et al. Clinical, immunological, and molecular analysis in a large cohort of patients with X-linked agammaglobulinemia: an Italian multicenter study. Clin Immunol. 2002;104:221-30.

12. Joshi AY, Iyer VN, Hagan JB, St Sauver JL, Boyce TG. Incidence and temporal trends of primary immunodeficiency: a populationbased cohort study. Mayo Clin Proc. 2009;84:16-22.

13. Gill JD. Newborn screening for SCID. The time is now. IDF Advocate. 2010;63:1-4.

14. Srinivasa BT, Alizadehfar R, Desrosiers M, Shuster J, Pai NP, Tsoukas CM. Adult primary immune deficiency: what are we missing? Am J Med. 2012;125:779-86.

15. Immune Deficiency Foundation. April is national primary immunodeficiency month. 2013. http://primaryimmune.org/april-isnational-primary-immunodeficiency-awareness-month. Accessed 31 March 2015.

16. Jeffrey Modell Foundation. PI Awareness Campaign. 2014. http:// www.info4pi.org/picampaign/index.cfm?section=campaign. Accessed 31 March 2015.

17. McGhee SA, Stiehm ER, McCabe ER. Potential costs and benefits of newborn screening for severe combined immunodeficiency. J Pediatr. 2005; 147:603-8.

18. Green NS, Rinaldo P, Brower A, Boyle C, Dougherty D, LloydPuryear M, et al. Committee report: advancing the current recommended panel of conditions for newborn screening. Genet Med. 2007;9:792-6.

19. Puck JM, SCID Newborn Screening Working Group. Populationbased newborn screening for severe combined immunodeficiency: steps toward implementation. J Allergy Clin Immunol. 2007;120: $760-8$.

20. Baker MW, Grossman WJ, Laessig RH, Hoffman GL, Brokopp $\mathrm{CD}$, Kurtycz DF, et al. Development of a routine newborn screening protocol for severe combined immunodeficiency. J Allergy Clin Immunol. 2009;124:522-7.

21. Baker MW, Laessig RH, Katcher ML, Routes JM, Grossman WJ, Verbsky J, et al. Implementing routine testing for severe combined immunodeficiency within Wisconsin's newborn screening program. Public Health Rep. 2010;125 Suppl 2:88-95.

22. Lipstein EA, Vorono S, Browning MF, Green NS, Kemper AR, Knapp AA, et al. Systematic evidence review of newborn screening and treatment of severe combined immunodeficiency. Pediatrics. 2010;125:e1226-35. 
23. Verbsky JW, Baker MW, Grossman WJ, Hintermeyer M, Dasu T, Bonacci B, et al. Newborn screening for severe combined immunodeficiency; the Wisconsin experience (2008-2011). J Clin Immunol. 2012;32:82-8.

24. Immune Deficiency Foundation. IDF SCID Newborn Screening Campaign. Available at: http://primaryimmune.org/idf-advocacycenter/idf-scid-newborn-screening-campaign/. Accessed 31 March 2015.

25. Borte S, von Döbeln U, Fasth A, Wang N, Janzi M, Winiarski J, et al. Neonatal screening for severe primary immunodeficiency diseases using high-throughput triplex real-time PCR. Blood. 2012;119:2552-5.

26. van Zelm MC, van der Burg M, Langerak AW, van Dongen JJ. PID comes full circle: applications of $\mathrm{V}(\mathrm{D}) \mathrm{J}$ recombination excision circles in research, diagnostics and newborn screening of primary immunodeficiency disorders. Front Immunol. 2011;2:12.

27. Reda SM, El-Ghoneimy DH, Afifi HM. Clinical predictors of primary immunodeficiency diseases in children. Allergy Asthma Immunol Res. 2013;5:88-95.

28. Subbarayan A, Colarusso G, Hughes SM, Gennery AR, Slatter M, Cant AJ, et al. Clinical features that identify children with primary immunodeficiency diseases. Pediatrics. 2011;127:810-6.

29. Jeffrey Modell Foundation. 10 Warning signs of primary of primary immunodeficiency. 2014. Available at: http://www.info4pi.org/ library/educational-materials/10-warning-signs. Accessed 31 March 2015

30. Bonilla FA, Bernstein IL, Khan DA, Ballas ZK, Chinen J, Frank $\mathrm{MM}$, et al. Practice parameter for the diagnosis and management of primary immunodeficiency. Ann Allergy Asthma Immunol. 2005;94(5 Suppl 1):S1-63.

31. US Government Printing Office. Electronic Code of Federal Regulations. 2014. Part 493.927 - Laboratory Requirements/ General Immunology. http://www.ecfr.gov/cgi-bin/retrieveECFR? $\mathrm{gp}=1 \& \mathrm{SID}=8 \mathrm{ad} 4874 \mathrm{c} 7299 \mathrm{a} 6 \mathrm{e} 7 \mathrm{e} 3 \mathrm{bb} 5211 \mathrm{e} 8 \mathrm{f} 30 \mathrm{fa} 0 \& \mathrm{~h}=\mathrm{L} \& \mathrm{n}=$ 42y5.0.1.1.9\&r=PART\&ty=HTML\#42:5.0.1.1.9.8.23.12. Accessed 31 March 2015.

32. Westgard QC. CLIA requirements for analytical quality. 2014. General Immunology/analytical quality requirements. https:// www.westgard.com/clia.htm. Accessed 31 March 2015.

33. Wadsworth Center. New York State Department of Health. Clinical laboratory evaluation program. 2013. Diagnostic Immunology/ Criteria for acceptable performance. http://www.wadsworth.org/ labcert/clep/ProgramGuide/CLEPGUIDE2013.pdf. Accessed 31 March 2015.

34. Cunningham-Rundles C, Sidi P, Estrella L, Doucette J. Identifying undiagnosed primary immunodeficiency diseases in minority subjects by using computer sorting of diagnosis codes. J Allergy Clin Immunol. 2004;113:747-55.

35. Immune Deficiency Foundation. Primary immune deficiency diseases in America: 2007. The third national survey of patients. Available at: https://primaryimmune.org/wp-content/uploads/2011/ 04/Primary-Immunodeficiency-Diseases-in-America-2007TheThird-National-Survey-of-Patients.pdf. Accessed 31 March 2015.
36. Primary Immunodeficiency Association. Patient survey: executive summary. 2011. http://www.pia.org.uk. Accessed 31 March 2015.

37. Chapel H, Lucas M, Lee M, Bjorkander J, Webster D, Grimbacher B, et al. Common variable immunodeficiency disorders: division into distinct clinical phenotypes. Blood. 2008;112:277-86.

38. Borte S, Wang N, Oskarsdóttir S, von Döbeln U, Hammarström L. Newborn screening for primary immunodeficiencies: beyond SCID and XLA. Ann N Y Acad Sci. 2011;1246:118-30.

39. Borte S, Janzi M, Pan-Hammarström Q, von Döbeln U, Nordvall L, Winiarski J, et al. Placental transfer of maternally-derived IgA precludes the use of Guthrie card eluates as a screening tool for primary immunodeficiency diseases. PLoS One. 2012;7, e43419.

40. Janzi M, Sjöberg R, Wan J, Fischler B, von Döbeln U, Isaac L, et al. Screening for C3 deficiency in newborns using microarrays. PLoS One. 2009;4, e5321.

41. Nyland JF, Wang SB, Shirley DL, Santos EO, Ventura AM, de Souza JM, et al. Fetal and maternal immune responses to methylmercury exposure: a cross-sectional study. Environ Res. 2011;111: $584-9$.

42. Kawikova I, Grady BP, Tobiasova Z, Zhang Y, Vojdani A, Katsovich L, et al. Children with Tourette's syndrome may suffer immunoglobulin A dysgammaglobulinemia: preliminary report. Biol Psychiatry. 2010;67:679-83.

43. Islam SK, Hossain KJ, Kamal M, Ahsan M. Serum immunoglobulins and white blood cells status of drug addicts: influence of illicit drugs and sex habit. Addict Biol. 2004;9:27-33.

44. Wu TL, Tsao KC, Chang CP, Li CN, Sun CF, Wu JT. Development of ELISA on microplate for serum C-reactive protein and establishment of age-dependent normal reference range. Clin Chim Acta. 2002;322:163-8.

45. Hossain MA, Emara M, El Moselhi H, Shoker A. Comparing measures of cystatin C in human sera by three methods. Am J Nephrol. 2009;29:381-91.

46. Chambers AG, Percy AJ, Yang J, Camenzind AG, Borchers CH. Multiplexed quantitation of endogenous proteins in dried blood spots by multiple reaction monitoring mass spectrometry. Mol Cell Proteomics. 2013;12(3):781-91.

47. Marques BL, Brandão CU, Silva EF, Marques VA, VillelaNogueira CA, Do ÓKM, et al. Dried blood spot samples: optimization of commercial EIAs for hepatitis $\mathrm{C}$ antibody detection and stability under different storage conditions. J Med Virol. 2012;84: 1600-7.

48. McDade TW, Woodruff TK, Huang YY, Funk WE, Prewitt M, Kondapalli L, et al. Quantification of anti-Müllerian hormone $(\mathrm{AMH})$ in dried blood spots: validation of a minimally invasive method for assessing ovarian reserve. Hum Reprod. 2012;27: 2503-8.

49. Lin YQ, Zhang Y, Li C, Li L, Zhang K, Li S. Evaluation of dry blood spot technique for quantification of an anti-CD20 monoclonal antibody drug in human blood samples. J Pharmacol Toxicol Methods. 2012;65:44-8. 